\title{
Comparison of the ultrashort gonadotropin- releasing hormone agonist-antagonist protocol with microdose flare -up protocol in poor responders: a preliminary study
}

\section{Zayıf over cevaplı hastalarda ultra kisa GnRH agonist/antagonist protokolünün mikrodoz flare up protokolü ile karşılaştınlması}

\author{
Bülent Berker ${ }^{1}$, Candan İltemir Duvan², Cemil Kaya ${ }^{3}$, Ruşen Aytaç${ }^{1}$, Hakan Şatıroğlu ${ }^{1}$ \\ ${ }^{1}$ Centre of Artificial Reproduction, Ankara University, Ankara, Turkey \\ ${ }^{2}$ Centre of Artificial Reproduction, Fatih University, Ankara, Turkey \\ ${ }^{3}$ Department of Obstetrics and Gynecology, Ufuk University, Ankara, Turkey
}

\section{Abstract}

Objective: To determine the potential effect of the ultrashort gonadotropin-releasing hormone (GnRH) agonist/GnRH antagonist protocol versus the microdose $\mathrm{GnRH}$ agonist protocol in poor responders undergoing intracytoplasmic sperm injection (ICSI).

Material and Methods: The patients in the Agonist-Antagonist Group ( $n=41)$ were administered the ultrashort GnRH-agonist/ antagonist protocol, while the patients in the Microdose Group $(n=41)$ were stimulated according to the microdose flare-up protocol. The mean number of mature oocytes retrieved was the primary outcome measure. Fertilization rate, implantation rate per embryo and clinical pregnancy rates were secondary outcome measures.

Results: There was no differenc between the mean number of mature oocytes retrieved in the two groups. There were also no statistical differences between the two groups in terms of peak serum $E_{2}$ level, canceled cycles, endometrial thickness on hCG day, number of 2 pronucleus and number of embryos transferred. However, the total gonadotropin consumption and duration of stimulation were significantly higher with the Agonist-Antagonist Group compared with the Microdose Group. The implantation and clinical pregnancy rates were similar between the two groups.

Conclusion: Despite the high dose of gonadotropin consumption and longer duration of stimulation with the ultrashort GnRH agonist/ antagonist protocol, it seems that the Agonist-Antagonist Protocol is not inferior to the microdose protocol in poor responders undergoing ICSI. (J Turkish-German Gynecol Assoc 2010; 11: 187-93)

Key words: Poor responder, mature oocytes, Agonist-Antagonist protocol, microdose flare-up protocol

Received: 11 August, 2010

Accepted: 19 November, 2010

\section{Introduction}

The management of the poor-responder patients still presents a challenging and frustrating problem in assisted reproductive technologies (ART). Poor ovarian response is unfortunately associated with a high rate of cycle cancellation
Özet

Amaç: ICSI uygulanan zayıf over cevaplı hastalarda ultra kısa GnRH agonist/GnRH antagonist protokolünün mikrodoz GnRH agonist protokolüne karşı potansiyel etkisini belirlemek.

Gereç ve Yöntemler: Mikrodoz grubundaki $(n=41)$ hastalar mikrodoz flare up protokolüne uygun olarak stimüle edilirken AgonistAntagonist grubundaki $(\mathrm{n}=41)$ hastalara da ultra kısa GnRH-agonist/ antagonist protokolü uygulandı. Bu çalışmanın primer sonuç değeri toplanan ortalama matür oosit sayısı iken, fertilizasyon oranı, embryo başına implantasyon oranı ve klinik gebelik oranı da sekonder sonuç değerleriydi.

Bulgular: İki grup arasındaki toplanan ortalama matür oosit saylanı arasında fark yoktu. Serum $\mathrm{E}_{2}$ düzeyleri, iptal edilen sikluslar, hCG günü endometrial kalınlığı, 2 pronukleus sayları ve transfer edilen embryo sayllarında da iki grup arasında istatistiksel farklılıklar yoktu. Bununla birlikte Agonist-Antagonist grubunda total gonadotropin tüketimi ve stimülasyon süresi Mikrodoz grubuyla karşılaştırıldığında belirgin olarak daha yüksekti. İki grup arasındaki implantasyon ve klinik gebelik oranları ise birbirine benzerdi.

Sonuç: Ultra kısa GnRH agonist/ antagonist protokolü ile yüksek doz gonadotropin tüketimi ve daha uzun süreli stimülasyona rağmen ICSI uygulanan zayıf over cevaplı hastalarda Agonist-Antagonist Protokolünün mikrodoz protokolünden daha az etkili olmadığı görülmektedir. (J Turkish-German Gynecol Assoc 2010; 11: 187-93)

Anahtar kelimeler: Zayıf over cevaplı, matür oositler, AgonistAntagonist protokol, mikrodoz flare-up protokol

Geliş Tarihi: 11 Ağustos 2010

Kabul Tarihi: 19 Kasım 2010

and decreased pregnancy rates $(1,2)$. Although there is no universally accepted definition for poor responders, a poor response to controlled ovarian hyperstimulation $(\mathrm{COH})$ might occur in a significant number of women undergoing ART, with a percentage ranging between $10 \%$ and $25 \%(2,3)$. The ideal approach to patients who respond poorly to traditional $\mathrm{COH}$ 
regimens in preparation for ART has not been clearly defined. Different treatment interventions have been proposed for these women to overcome the poor ovarian response during $\mathrm{COH}$. These options consisted of pituitary down-regulation protocols as gonadotropin-releasing hormone agonist (GnRH-a) stop protocols, microdose GnRH-a flare-up protocols or $\mathrm{GnRH}$ antagonists protocols and also adjuvant therapy regimes including growth hormone and letrazol $(4,5)$.

The most prevalent approaches for treating poor responder patients are microdose GnRH-a "flare" $(6,7)$ and GnRH antagonist protocol $(8,9)$. According to several studies, microdose GnRH-a flare-up regimes seem to be more successful in terms of ovarian response and/or pregnancy rates $(4,10)$. The basic hypothesis of this approach is the administration of the minimal dose of $\mathrm{GnRH}-\mathrm{a}$ necessary to induce gonadotropin release while minimizing premature ovulation. The other attractive treatment option for poor responders is the GnRH antagonist protocol. These agents act to block the pituitary gonadotrop receptors rapidly without any associated stimulatory effects. As the initiations of the GnRH-antagonists occur after the beginning of gonadotropin stimulation, their impact on early follicular recruitment is minimal (8).

Even in the original manuscript of Surrey describing the microdose flare protocol, no change in follicular phase testosterone, $\mathrm{LH}$, and progesterone levels were reported, but there are still some concerns about these issues (7, 11, 11-13). In a similar fashion, the GnRH antagonist protocol exposes the maturing oocytes to the patient's own endogenous androgen production, which is detrimental during the $6^{\text {th }}$ to $7^{\text {th }}$ days of stimulation before development of a mature follicle (14). In addition, the impact of these protocols on endometrial receptivity also remains controversial $(15,16)$. As a result, neither of these protocols has been effective in improving ART outcomes in this subgroup of patients $(7,17,18)$.

The idea of the combination of the microdose GnRH-a flare-up and $\mathrm{GnRH}$ antagonist protocol to minimize these detrimental effects and to combine the beneficial effects of these two stimulation protocols for poor responders was first presented by Berger et al. as a novel protocol - the "Agonist-Antagonist Protocol (AAP)" (19).

Up tol date, there have been no randomized, prospective published data comparing the novel AAP and microdose GnRH-flareup protocols in poor responders undergoing intracytoplasmic sperm injection (ICSI). Therefore, in this randomized prospective study, we aim to compare the efficacy of the ovarian stimulation by ultrashort GnRH agonist-antagonist with microdose flare-up protocol in poor responders undergoing ICSI.

\section{Material and Methods}

\section{Patients and study design}

Between September 2006 and April 2008, a total of 82 poor responder patients who underwent intracytoplasmic sperm injection cycles (ICSI) were included. All patients underwent precycle ovarian reserve testing, which included an assessment of cycle day 3 serum follicle-stimulating hormone (FSH) and $\mathrm{E}_{2}$ levels and a measurement of ovarian volume and number of antral follicles counting by transvaginal ultrasound during the follicular phase. Criteria for classification as a poor responder included at least one of the following: day 3 serum FSH level
$>10 \mathrm{mIU} / \mathrm{mL},<6$ total antral follicles, prior cycle cancellation, prior poor response to $\mathrm{COH}$ (peak $\mathrm{E}_{2}<500 \mathrm{pg} / \mathrm{mL}$ and/or $<6$ oocytes retrieved), and age $>41$ (18). The study was approved by the Institutional Review Board of the University. All patients received adequate counseling regarding the stimulation regimens and signed informed consent forms.

Patients were excluded from the study if they had only one ovary, a body mass index higher than 30 , polycystic ovary syndrome, stage III-IVendometriosis, endocrine or metabolic disease, chromosomal disorders and patients whose partners were azospermic.

A method of computer-generated block randomization using sealed envelopes was employed. Patients were assigned in a 1:1 ratio to either an ultrashort GnRH agonist/GnRH antagonist group or microdose flare up protocol. Sealed envelopes with treatment allocation instructions were opened on the day of stimulation initiation by a nurse who assigned participants to their groups and was responsible for coding protection.

\section{Treatment protocols}

The patients in theultrashort GnRH agonist/GnRH antagonist group $(n=41)$ were administered the ultrashort GnRH-agonist/ GnRH antagonist protocol. The ultrashort GnRH-agonist/ GnRH antagonist protocol entailed the administration of leuprolide acetate (LA, Lucrin; Abbott, Cedex, France) at 40 microg sc/ bid, started on the second day of menses and continued for 3 consecutive days, followed by gonadotropins, which were initiated on the last day of LA administration with maximal doses continuing until hCG day. Once the leading follicle had reached a size of $14 \mathrm{~mm}$, cotreatment was initiated with the GnRHantagonist cetrorelix (Cetrotide; Serono, Turkey) at $0.25 \mathrm{mg} / \mathrm{day}$, which was continued up to hCG injection. A schematic for this protocol is provided in Figure 1.

The patients in the Microdose Group ( $n=41)$, who started to use 40 microg sc/bid LA on the second day of menses and two days after initiation of GnRH-a, gonadotropin stimulation was initiated and continued until hCG day. A schematic representation for this protocol is provided in Figure 2. In general, the starting dose of recombinant FSH (Gonal-F; Serono, Istanbul, Turkey) was determined depending on the age, body mass index and ovarian response to previous cycle (if present) and increased to a maximum of $450 \mathrm{IU} /$ day depending on the ovarian response. The dosage of gonadotrophins was individualized after day 5 according to ultrasonographic and hormonal follow-ups of the follicular growth. Once at least three follicles $>17 \mathrm{~mm}$ in diameter were achieved, 10,000 IU of human chorionic gonadotrophin (Choragon, Ferring, Kiel, Germany) were administered and transvaginal ultrasound guided oocyte recovery was scheduled for $35.5 \mathrm{~h}$ later.

\section{Embryo culture and transfer}

Standard intracytoplasmic sperm injection (ICSI) was performed as clinically appropriate. Gametes and embryos were cultured in a sequential G medium (Vitrolife, Englewood, CO) and incubated in 6\% CO2, 5\% O2, and 89\% N2. Embryo transfer was performed on day 3 after oocyte collections. Embryo transfers were performed under ultrasound guidance using a Wallace catheter (Marlow, Willoughby, OK). Luteal support was given by daily vaginal progesterone (crinone $\% 8$ gel, Serono). Luteal support was initiated on the day of oocyte retrieval and continued 


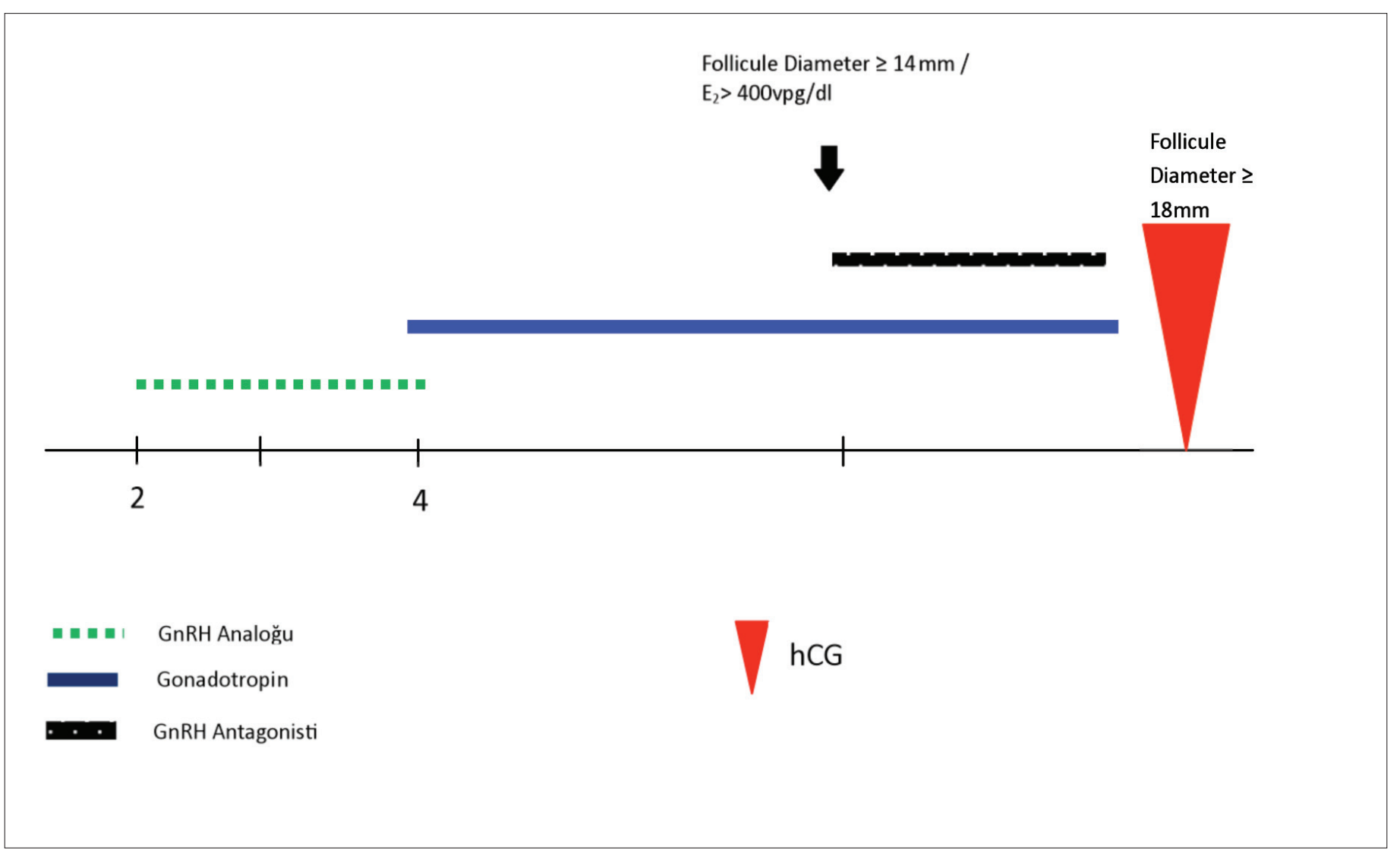

Figure 1. Schematic representation of the Agonist-Antagonist Protocol

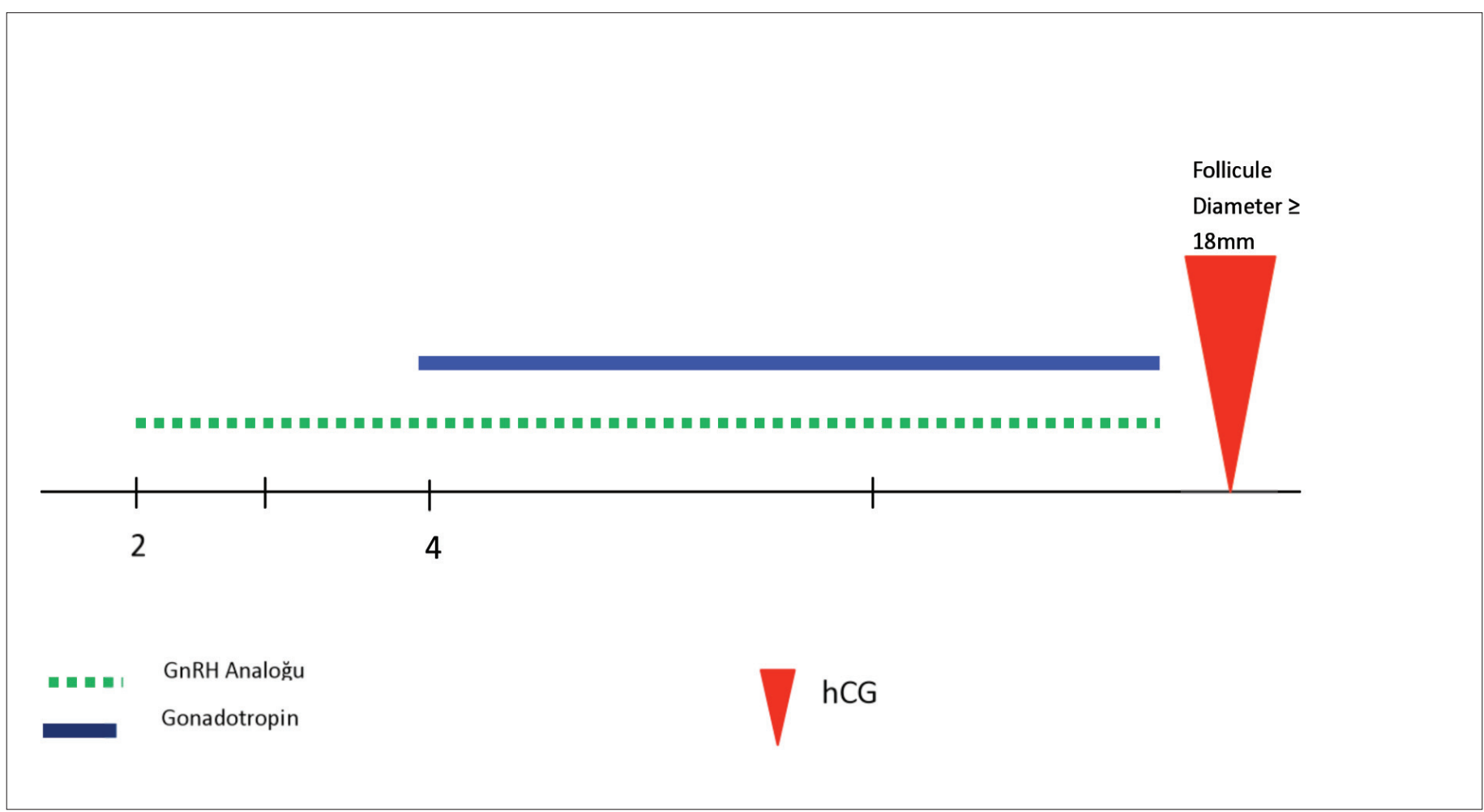

Figure 2. Schematic representation of the Microdose GnRH-a flare-up protocol 
until the day of pregnancy testing and if the test was positive, progesterone treatment was continued up to 12 gestational weeks. Pregnancy tests were performed 14 days after oocyte retrieval. Clinical pregnancies were confirmed by transvaginal ultrasound examination at 4.5 weeks from oocyte retrieval with the number of gestational sacs and cardiac activity noted.

FSH was measured by a chemiluminescent immunometric assay with Immulite One, Bio-DPC, Siemens, USA. Analytical sensitivity: $0.1 \mathrm{mIU} / \mathrm{ml}$. The inter assay and intra assay coefficients of variation were $5.6 \%$ and $3.1 \%$.

\section{Statistical analysis}

Although the primary aim of this study was to compare the overall pregnancy rate per groups, to assess a difference in pregnancy rates between the protocols, a prior power calculation estimated that any sample size of between 160 and 348 would show a $10 \%$ difference with $80 \%$ power $(\alpha=0.05)$. Considering the rare occurrence of poor responders, it should take a considerably long time to be able to collect large samples in this subject, so we preferred to focus on oocyte numbers as a main outcome measure. The primary aim of this study was to compare by means of the number of mature oocytes A total sample size of 54 cases (27 for Agonist-Antagonist Group, 27 for Microdose Group) was required to detect a difference in means of $1.0(\mathrm{SD}=1.58)$ with a power of $80 \%$ at the $5 \%$ significance level using a two-sided Mann-Whitney test, assuming that the actual distribution is double exponention.

Statistical analysis was performed by Statistical Package for Social Sciences (SPSS) 11.5 software (SPSS Inc., Chicago, IL, United States). Whether the continuous variables were normally distributed or not were determined by using Shapiro Wilk test. Continuous variables were expressed as mean \pm standard deviation or median (minimum-maximum), where applicable. Nominal data were presented as the number of cases and (\%). Whereas the differences between groups regarding normally distributed data were tested by Student's t test, non-normally distributed data were evaluated by Mann Whitney $U$ test. Nominal data were analyzed by Pearson Chi-square test. A p value less than 0.05 was considered as statistically significant.

\section{Results}

A total of 82 poor responder patients underwent $78 \mathrm{COH}-\mathrm{ICSI}$ cycles. Of these patients, 41 received the ultrashort GnRH agonist/GnRH antagonist protocol and 41 received the microdose flare-up protocol. The cycle cancellation was done for two patients in the AAP $(n=39)$ group (one due to poor folliculogenesis, and one to fertilization failure), two patients in the Microdose Group $(n=39$, one cycle owing to premature $\mathrm{LH}$ surge, one cycle owing to poor folliculogenesis). Cycle cancellation rates were similar in the groups.

The mean number of mature oocytes retrieved was similar in the two groups $(7.1 \pm 4.9$ in AAP Group; $7.4 \pm 6.0$ in Microdose Group; $\mathrm{p}>0.05)$. There were no statistical differences in age, BMI, day 3 FSH and estradiol levels between the two groups. Demographic data of the patients are displayed in Table 1. There were also no statistical differences between the two groups in terms of peak $\mathrm{E}_{2}$ level, endometrial thickness on hCG day, number of $2 \mathrm{PN}$ and number of embryos transferred. However, the duration of stimulation $(10.51 \pm 2.4$ vs. $9.05 \pm 2.61$, respectively) and total consumption of the gonadoptrophin doses (3365.93 \pm 1627.59 v. 2327.02 \pm 929.46 ; $p=0.004)$ were significantly higher in the AAP Group (Table 2). The rate of top-quality embryo (Grade A; at least seven cells and $<10 \%$ fragmentation on day 3) transferred, fertilization rate and implantation rate per embryo were similar between the groups (Table 3). However, pregnancy rate was higher in the microdose GnRH-a flare-up protocol than in AAP, but it did not reach the significant level (19.5\% vs $26.3 \%$, respectively).

\section{Discussion}

To the best of our knowledge, this is the first study comparing the AAP with the microdose GnRH-a flare-up protocol in poor responders. In the current study, we showed that the mean number of mature oocytes retrieved were similar between two groups. The results of our study further indicated that clinical pregnancy rates were also similar between the groups.

The idea of minimizing the dose of the GnRH agonist agents created the so-called 'mini' and 'micro' dose flare-up GnRH

Table 1. Demographic characteristics of the patients in both groups

\begin{tabular}{|l|c|c|c|}
\hline & Agonist-Antagonist & Microdose flare-up & p \\
\hline Number of patients (n) & 41 & 41 & \\
\hline Number of cycles (n) & 39 & 39 & 0.63 \\
\hline Age (years) & $35.21 \pm 6.07$ & $35.81 \pm 4.84$ & 0.39 \\
\hline Number of patients aged >35(years) & 18 & 21 & 0.52 \\
\hline BMI $\left(\mathrm{kg} / \mathrm{m}^{2}\right.$ ) & $26.69 \pm 4.20$ & $25.93 \pm 4.53$ & 0.98 \\
\hline Infertility period (years) & $9.1 \pm 5.68$ & $9.28 \pm 6.39$ & 0.09 \\
\hline Day 3 FSH (mIU/mL) & $10.03 \pm 8.05$ & $7.32 \pm 2.95$ & 0.56 \\
\hline Number of patients >FSH 10 (n) & 13 & 12 & 0.37 \\
\hline Day 3 Estradiol (pgmol/L) & $51.5 \pm 27.45$ & $1.57 \pm 0.82$ & 0.54 \\
\hline Cycle number & $1.71 \pm 0.94$ & \\
\hline *Statistical significance was defined as $p<0.05$. Data were shown as mean \pm SD. Groups were compared using Student's tor Mann Whitney U test, where appropriate \\
\hline
\end{tabular}


Table 2. The ovarian stimulation cycle characteristics in both groups

\begin{tabular}{|l|c|c|c|}
\hline Parameter & Agonist-Antagonist & Microdose flare-up & p \\
\hline Days of stimulation (n) & $10.51 \pm 2.4$ & $9.05 \pm 2.61$ & $<0.05$ \\
\hline Gonadotropin administrated (IU) & $3365.93 \pm 1627.59$ & $2327.02 \pm 929.46$ & $<0.05$ \\
\hline Canceled cycle (n) & 2 & 2 & NS \\
\hline Peak estradiol (pg/ml) on hCG day & $1370.86 \pm 718.64$ & $2029.57 \pm 1365.78$ & NS \\
\hline Endometrial thickness on hCG day (mm) & $9.68 \pm 1.43$ & $9.83 \pm 2.47$ & NS \\
\hline Number of oocytes retrieved (n) & $7.82 \pm 5.24$ & $8.52 \pm 6.38$ & NS \\
\hline Number of mature oocytes (n) & $7.16 \pm 4.94$ & $7.4 \pm 6$ & NS \\
\hline Number of 2PN & $3.54 \pm 3.39$ & $4.17 \pm 4.2$ & NS \\
\hline $\begin{array}{l}\text { *NS, Not significant. Statistical significance was defined as p<0.05. Data were shown as mean } \pm \text { SD. Groups were compared using Student's tor Mann Whitney } \\
\text { U test, where appropriate }\end{array}$ & & \\
\hline
\end{tabular}

Table 3. Clinical pregnancy and implantation rates in groups

\begin{tabular}{|l|c|c|c|}
\hline Parameter & Agonist-Antagonist & Microdose flare-up & p \\
\hline Fertilization rate (\%) & 54 & 62 & NS \\
\hline Grade A embryo (\%) & 66 & 59 & NS \\
\hline Number of embryos transferred (n) & $2.62 \pm 1.37$ & $3.05 \pm 1.55$ & NS \\
\hline Implantation rate (\%) & 7.6 & 8.6 & NS \\
\hline Clinical Pregnancy rate /cycle(\%) & $19.5(8 / 41)$ & $26.3(10 / 38)$ & NS \\
\hline *NS, Not significant. Statistical significance was defined as p<0.05. Groups were compared using Student's t or Mann Whitney U test, where appropriate \\
\hline
\end{tabular}

agonist regimens. A microdose flare-up regimen has been proposed and used successfully in poor responders. The basic hypothesis of this approach is the administration of the minimal dose of GnRH-a necessary to induce gonadotropin release while minimizing premature ovulation. This approach takes advantage of the initial release of endogenous gonadotropins induced by low-dose GnRH-a administration in the early follicular phase, in an effort to enhance response to the subsequent administration of exogenous gonadotropins $(7,18,20)$. Although this flare effect enhances follicular recruitment, it can result in premature luteinization and thus compromise the cycle (21). This approach has also some disadvantages such as increased serum LH levels, with a concomitant increase in serum progesterone and testosterone levels during the early follicular maturation (i.e., flare effect), which in turn may affect oocyte quality (11-13).

The incorporation of GnRH antagonists represents an appealing alternative to agonists in the management of the poor responder. The addition of the $\mathrm{GnRH}$ antagonist to stimulation protocols prevents premature LH surges, without causing suppression in the early follicular phase, a crucial time for poorresponder patients (22). The results of GnRH antagonists for poor responders indicate the possibility of reducing the amount of gonadotropins, the length of stimulation, the number of cancelled cycles, and the overall cost normally associated with the long protocol (23-27). However, the issue of the reported lower clinical pregnancy and implantation rates in the earlier studies comparing antagonist and agonist protocols is still not resolved. In the literature, there are several controlled studies comparing microdose flare and antagonist protocols and antagonist plus letrosole in the recent literature. For example, Demirol et. al. reported that the microdose flare-up protocol seems to have a better outcome in poor-responder patients, with a significantly higher mean number of mature oocytes retrieved and higher implantation rate. (28). In another study, Malmusi et al. also reported that, in terms of mature oocytes retrieved, fertilization rate, and top-quality embryos transferred in poor-responder patients, the flare-up protocol appears to be more effective than the GnRH-antagonist protocol (29). On the other hand, Kahraman et al. found that the microdose $\mathrm{GnRH}$-a flare-up protocol and multiple dose $\mathrm{GnRH}$ antagonist protocol seem to have similar efficacy in improving treatment outcomes of poor responder patients (30).

Schoolcraft et al. also compared the efficacy of a microdose GnRH agonist flare (ML) with a GnRH antagonist/letrozole (AL) protocol in poor responders, and reported that stimulation between the microdese and antagonist-letrazol protocols were equivalent, with the exception of peak $\mathrm{E}_{2}$ levels. However, the higher ongoing pregnancy rates and trend toward superior implantation rates would suggest that microdose represents a preferred approach for the poor responder (4). However, in another study from Yarali et al. İt was reported that, in terms of the high fertilization rate and the rate of at least one top-quality embryo transferred in the $\mathrm{GnRH}$ antagonist/letrozole protocol, compared with the mirodose protocol the $\mathrm{GnRH}$ antagonist/ letrozole protocol is an effective protocol that may be used in poor ovarian responders for ICSI (31).

Although as in the above studies, several trials investigated the microdose flare and antagonist protocols or antagonist plus 
letrozole protocol in poor responders, only a limited number of studies in the literature investigated combining the ultrashort GnRH agonist-antagonist protocols in poor responders $(17,19,32)$. The report by Berger et al. (19), which is the first report dealing with the AAP protocol, was presented only as a meeting abstract, so no data exists concerning the stimulation characteristics of the control cycles. Similarly, Orvieto et al. (17) evaluated the role of the ultrashort GnRH-agonist flare protocol combined with the flexible multidose GnRH-antagonist protocol in patients who had responded poorly to a previous IVF attempt. In contrast to our study, their AAP protocol entailed depot analog (triptorelin $0.1 \mathrm{mg} /$ day) as a GnRH-a. In addition, they did not report any information regarding the patients' previous stimulation protocols. In 2005, Erden et al. in their retrospective study, compared the Agonist-Antagonist Protocol and microdose flare-up protocols in poor responder IVF patients (32). They reported that there were higher peak estradiol levels, more mature and fertilized oocytes and higher clinical pregnancy rates in the Agonist-Antagonist Protocol. Unfortunately, this study was presented only as an oral presentation. All the above studies had found statistically significantly higher numbers of oocytes retrieved and embryos transferred in the ultrashort GnRH agonist-antagonist group. In contrast to previous studies, we did not detect any differences in terms of stimulation and reproductive outcome parameters. The small number of patients in the studies with differences in the treatment period and in different antagonist protocols may explain these discrepancies. In addition, one of the difficulties in critically evaluating various $\mathrm{COH}$ protocols is the lack of a single universally accepted definition of 'poor responder' (5). A variety of criteria have been used alone or in combination as inclusion criteria for proposed protocols. In our study, in contrast to the previous studies, not only the previous IVF failure but other poor response markers were also used as inclusion criteria. It is possible that results may differ with the application of more strict criteria for this patient group. However, the definitions for poor responders employed in this trial are consistent with those employed in Schoolcraft et al.'s previously published evaluation of a microdose flare-up regime (18).

In this study, the women in the ultrashort $\mathrm{GnRH}$ agonist/ $\mathrm{GnRH}$ antagonist protocol had a longer treatment duration and required significantly more gonadotropin, but had the same mean number of metaphase II oocytes retrieved as did women in the microdose flare-up protocol. Thus, the follicular response was slower in the ultrashort GnRH agonist/GnRH antagonist group. Prolongation of the follicular phase in patients stimulated with rec-FSH and GnRH antagonist for IVF does not affect oocyte or embryo quality (33). In our results, the implantation and clinical pregnancy rate per cycle were also similar between groups. Differences of our study from other microdose protocols may include not using oral contraceptive (OC) pretreatment during GnRHa in the flare-up protocol. As in our previous published study, which reported that OC pretreatment plus microdose GnRHa in the flare-up protocol does not offer advantages over non-OC microdose GnRHa in the flare-up protocol among poor responder ICSI patients, we also did not use oral contraception in the microdose protocol. In our previous study, we found no significant differences between groups in the number of oocytes, peak estradiol levels, endometrial thicknesses, fertilization rates and embryo qualities. Furthermore, implantations and pregnancy rates per embryo transfer were similar. As a result of our previous study, we thought that this preference should not affect the outcomes of the microdose protocol negatively (34).

The major weakness of our study is the limited number of couples undergoing the ICSI procedures investigated. Thus, we consider that the results of this study could be significant if the number of patients per group were increased.

In conclusion, the most convenient $\mathrm{COH}$ protocol for poor responder patients is still unclear. According to our preliminary study, in terms of primary outcome measure, this protocol seems to be equal to the microdose protocol, but in terms of secondary outcome measures there are statistically significant differences in terms of gonadotropin consumption and duration of stimualtion in favor of the microdose flare protocol. Hence, we may consider that, in the event of high doses of gonadotrophin consumption and long duration of stimulation, AAP protocols seem to be valuable alternatives for poor responders. , This novel protocol may be offered especially to patients with a history of a failure with the microdose flare-up protocol. However, before making any recommendations; further large prospective randomized studies are needed to elucidate the exact role of the Agonist-Antagonist Protocols in poor responders.

\section{Conflict of interest}

No conflict of interest is declared by authors.

\section{References}

1. Jenkins JM, Davies DW, Devonport H, Anthony FW, Gadd SC, Watson $\mathrm{RH}$, et al. Comparison of "poor" responders with "good" responders using a standard buserelin/human menopausal gonadotrophin regime for in-vitro fertilization. Hum Reprod 1991; 6: 918-21.

2. Pellicer A, Lightman A, Diamond MP, Russell JB, DeCherney AH. Outcome of in vitro fertilization in women with low response to ovarian stimulation. Fertil Steril 1987; 47: 812-5.

3. Keay SD, Liversedge NH, Mathur RS, Jenkins JM. Assisted conception following poor ovarian response to gonadotrophin stimulation. Br J Obstet Gynaecol 1997; 104: 521-7.

4. Schoolcraft WB, Surrey ES, Minjarez DA, Stevens JM, Gardner DK. Management of poor responders: can outcomes be improved with a novel gonadotropin-releasing hormone antagonist/letrozole protocol? Fertil Steril 2008; 89: 151-6.

5. Surrey ES, Schoolcraft WB. Evaluating strategies for improving ovarian response of the poor responder undergoing assisted reproductive techniques. Fertil Steril 2000; 73: 667-76.

6. Padilla SL, Dugan K, Maruschak V, Shalika S, Smith RD. Use of the flare-up protocol with high dose human follicle stimulating hormone and human menopausal gonadotropins for in vitro fertilization. Fertil Steril 1996; 65: 796-9.

7. Surrey ES, Bower J, Hill DM, Ramsey J, SurreyMW. Clinical and endocrine effects of a micro dose GnRH agonist flare regimen administered to poor responders who are undergoing in vitro fertilization. Fertil Steril 1998; 69: 419-24.

8. Diedrich K, Diedrich C, Santos E, Zoll C, al-Hasani S, Reissman T, et al. Suppression of the endogenous luteinizing hormone surge by the gonadotropin releasing hormone antagonist Cetrorelix during ovarian stimulation. Hum Reprod 1994; 9: 788-91.

9. Fluker M, Grifo J, Leader A, Levy M, Meldrum D, Mushauer SJ, et al. Efficay and safety of ganirelix acetate versus leuprolide acetate in women undergoing controlled ovarian hyperstimulation. Fertil Steril 2001; 7: 38-45. 
10. Detti L, Williams DB, Robins JC, Maxwell RA, Thomas MA. Comparison of three downregulation approaches for poor responders undergoing in vitro fertilization. Fertil Steril 2005; 84: 1401-5.

11. Shoham Z, Jacobs HS, Insler V. Luteinizing hormone: its role, mechanism of action, and detrimental effects when hypersecreted during the follicular phase. Fertil Steril 1993; 59: 1153-61.

12. Erickson GF, Magoffin DA, Dyer CA, Hofeditz C. The ovarian androgen producing cells: a review of structure/function relationships. Endocr Rev 1985; 6: 371-99.

13. San Roman GA, Surrey ES, Judd HL, Kerin JF. A prospective randomized comparison of luteal phase versus concurrent follicular phase initiation of gonadotropin-releasing hormone agonist for in vitro fertilization. Fertil Steril 1992; 58: 744-9.

14. Kolibianakis EM, Albano C, Camus M, Tournaye H, Van Steirteghem AC, Devroey P. Initiation of gonadotropin releasing hormone antagonist on day 1 as compared to day 6 of the stimulation: effect on hormonal levels and follicular development in in vitro fertilization cycles. J Clin Endocrinol Metab 2003; 88: 5632-7.

15. Simon C, Oberye J, Bellver J, Vidal C, Bosch E, Horcajadas JA, et al. Similar endometrial development in oocyte donors treated with either high- or standard-dose GnRH antagonist compared to treatment with a GnRH agonist or in natural cycles. Hum Reprod 2005; 20: 3318-27.

16. Martinez-Conejero JA, Simon C, Pellicer A, Horcajadas JA. Is ovarian stimulation detrimental to the endometrium? Reprod Biomed Online 2007; 15: 45-50.

17. Orvieto R, Kruchkovich J, Rabinson J, Zohav E, Anteby EY, Meltcer S. Ultrashort gonadotropin-releasing hormone agonist combined with flexible multidose gonadotropin-releasing hormone antagonist for poor responders in in vitro fertilization/embryo transfer programs. Fertil Steril. 2008; 90: 228-30.

18. Schoolcraft W, Schlenker T, Gee M, Stevens J, Wagley L. Improved controlled ovarian hyperstimulation in poor responder in vitro fertilization patients with a microdose follicle stimulating hormone flare, growth hormone protocol. Fertil Steril 1997; 67: 93-7.

19. Berger BM, Ezcurra D, Alper MM. The agonist-antagonist protocol: a novel protocol for treating the poor responder [abstract]. Fertil Steril 2004; 82(Suppl 2): S126.

20. Scott R, Navot D. Enhancement of ovarian responsiveness with microdoses of gonadotropin-releasing hormone agonists during ovulation induction for in vitro fertilization. Fertil Steril 1994; 61: 880-5.

21. Loumaye E, Vankrieken L, Depreester S, Psalti I, de Cooman S, Thomas K. Hormonal changes induced by short-term administration of gonadotropin-releasing hormone agonist during ovarian hyperstimulation for in vitro fertilization and their consequences for embryo development. Fertil Steril 1989; 51: 105-11.

22. Akman MA, Erden HF, Tosun SB, Bayazit N, Aksoy E, Bahceci M. Addition of GnRH antagonist in cycles of poor responders undergoing IVF. Hum Reprod 2000; 15: 2145-7.
23. Craft I, Gorgy A, Hill J, Menon D, Podsiadly B. Will GnRH antagonists provide new hope for patients considered "difficult responders" to GnRH agonist protocols? Hum Reprod 1999; 14: 2959-62.

24. Nikolettos N, Al-Hasani S, Felberbaum R, Demirel LC, Kupker W, Montzka P, et al. Gonadotropin-releasing hormone antagonist protocol: a novel method of ovarian stimulation in poor responders. Eur J Obstet Gynecol Reprod Biol 2001; 97: 202-7.

25. Al-Inany $\mathrm{H}$, Aboulghar $\mathrm{M}$. GnRH antagonist in assisted reproduction: a Cochrane review. Hum Reprod 2002; 17: 874-85.

26. Chang PL, Zeitoun KM, Chan LK, Thornton MH II, Sauer MV. GnRH antagonist in older IVF patients. Retrieval rates and clinical outcome. J Reprod Med 2002; 47: 253-8.

27. Marci R, Caserta D, Dolo V, Tatone C, Pavan A, Moscarini M. GnRH antagonist in IVF poor-responder patients: results of a randomized trial. Reprod Biomed Online 2005; 11: 189-93.

28. Demirol A, Gurgan T. Comparison of microdose flare-up and antagonist multiple-dose protocols for poor-responder patients: a randomized study. Fertil Steril 2009 ; 92: 481-5.

29. Malmusi S, La Marca A, Giulini S, Xella S, Tagliasacchi D, Marsella $\mathrm{T}$, et al. Comparison of a gonadotropin-releasing hormone (GnRH) antagonist and $\mathrm{GnRH}$ agonist flare-up regimen in poor responders undergoing ovarian stimulation. Fertil Steril 2005; 84: 402-6.

30. Kahraman K, Berker B, Atabekoglu CS, Sonmezer M, Cetinkaya E, Aytac R, Satiroglu H. Microdose gonadotropin-releasing hormone agonist flare-up protocol versus multiple dose gonadotropin-releasing hormone antagonist protocol in poor responders undergoing intracytoplasmic sperm injection-embryo transfer cycle. Fertil Steril 2009; 91: 2437-44.

31. Yarali H, Esinler I, Polat M, Bozdag G, Tiras B. Antagonist/letrozole protocol in poor ovarian responders for intracytoplasmic sperm injection: a comparative study with the microdose flare-up protocol. Fertil Steril 2009; 92: 231-5.

32. Erden HF, Akman MA, Bayazit N, Bahceci M. Efficacy of a New Agonist-Antagonist Protocol Compared To Microdose Flare-up in Poor Responder IVF Patients (Oral presentation). Fertil Steril 2005 Sep; 84, Suppl.(1).

33. Kolibianakis EM, Albano C, Camus M, Yournaye H, van steirteghem AC, Devroey P. Prolongation of the follicular phase in vitro fertilization results in a lower ongoing pregnancy rate in cycles stimulated with recombinant follicle stimulating hormone and gonadotropinreleasing hormone antagonist. Fertil Steril 2004; 82: 102-7.

34. Duvan CI, Berker B, Turhan NO, Satiroglu H. Oral contraceptive pretreatment does not improve outcome in microdose gonadotrophin-releasing hormone agonist protocol among poor responder intracytoplasmic sperm injection patients. J Assist Reprod Genet 2008; 25: 89-93. 